\title{
Effect of intrauterine infusion of ceftiofur on uterine health and fertility in dairy cows
}

\author{
K. N. Galvão, ${ }^{*}$ L. F. Greco,† J. M. Vilela,† M. F. Sá Filho,† and J. E. P. Santos ${ }^{1}$ \\ ${ }^{*}$ Department of Clinical Sciences, Cornell University, Ithaca, NY 14853 \\ †Department of Animal Sciences, University of Florida, Gainesville 32611
}

\begin{abstract}
Objectives were to determine the effects of intrauterine (i.u.) infusion of ceftiofur hydrochloride on uterine health and fertility of dairy cows already receiving $\mathrm{PGF}_{2 \alpha}$ for estrous synchronization. Holstein cows at $44 \pm 3 \mathrm{~d}$ in milk (DIM) were blocked by parity and diagnosis of metritis in the first 14 DIM and of other illnesses and, within each block, randomly assigned to 1 of 2 treatments: a single i.u. infusion of $125 \mathrm{mg}$ of ceftiofur hydrochloride at $44 \pm 3$ DIM (ceftiofur, $\mathrm{n}=396$ ), or no i.u. infusion (control, $\mathrm{n}=416$ ). All cows received $25 \mathrm{mg}$ of $\mathrm{PGF}_{2 \alpha}$ at $37 \pm 3$ and $51 \pm 3$ DIM as part of an estrous synchronization protocol. A subset of 547 cows was evaluated for clinical endometritis immediately before treatment, and 202 cows had an aseptic uterine sample collected before the injection of $\mathrm{PGF}_{2 \alpha}$ at 51 \pm 3 DIM for bacteriology and diagnosis of subclinical endometritis ( $\geq 5 \%$ neutrophils). Pregnancy on d $38 \pm$ 3 and $180 \pm 7$ after the first artificial insemination, pregnancy loss, and interval from calving to pregnancy in the first 300 DIM were evaluated. The proportions of cows diagnosed with clinical endometritis before treatment were similar between ceftiofur and control treatments. Intrauterine infusion with ceftiofur did not influence prevalence of subclinical endometritis and positive uterine culture $7 \mathrm{~d}$ after treatment; however, it reduced the prevalence of positive uterine culture in cows with clinical endometritis (29.0 vs. $51.4 \%)$ and reduced the overall prevalence of Arcanobacterium pyogenes (1.0 vs. $7.6 \%$ ) at $51 \pm 3$ DIM. Cows with clinical endometritis had increased prevalence of $A$. pyogenes (10.3 vs. $1.5 \%)$, Escherichia coli (5.9 vs. $0.75 \%)$, and overall positive uterine culture (41.2 vs. $22.4 \%$ ); however, cows with subclinical endometritis only had an increased prevalence of $A$. pyogenes (10.2 vs. 1.5\%). Ceftiofur did not affect pregnancy per artificial insemination in all cows or in cows previously diagnosed with metritis or clinical endometritis. Interval to pregnancy
\end{abstract}

Received August 8, 2008.

Accepted November 4, 2008.

${ }^{1}$ Corresponding author: jepsantos@ufl.edu was similar for control and ceftiofur cows. Intrauterine infusion of ceftiofur hydrochloride reduced the prevalence of uterine infection in cows with clinical endometritis, and the prevalence of $A$. pyogenes, but did not affect the prevalence of subclinical endometritis or fertility of dairy cows already receiving $\mathrm{PGF}_{2 \alpha}$.

Key words: ceftiofur hydrochloride, dairy cow, endometritis, reproduction

\section{INTRODUCTION}

Uterine diseases such as metritis and endometritis are highly prevalent in high-producing dairy cows and are associated with decreased pregnancy per AI, extended interval to pregnancy, increased culling, and economic losses (Bartlett et al., 1986; Sheldon and Dobson, 2004; Gilbert et al., 2005). In addition to clinical uterine disease, subclinical endometritis, which is characterized by increased proportion of polymorphonuclear neutrophils in uterine cytology, has a major detrimental effect on fertility of dairy cows (Kasimanickam et al., 2004; Gilbert et al., 2005; Rutigliano et al., 2008). Cows diagnosed with retained placenta and metritis early postpartum have twice the odds of developing subclinical endometritis after 30 DIM (Rutigliano et al., 2008).

A method to reduce the effect of uterine disease on fertility is intrauterine (i.u.) treatment with antibiotics. Intrauterine infusion of cephapirin benzathine, a first-generation cephalosporin, improved reproductive performance of cows with subclinical endometritis (Kasimanickam et al., 2005) or clinical endometritis (LeBlanc et al., 2002), and cows previously diagnosed with retained fetal membranes, stillbirths, or a vulval discharge after 13 DIM (McDougall, 2001). Although i.u. antibiotic therapy in cows with clinical and subclinical endometritis improved fertility, it is known that isolation of bacteria from the uterus of dairy cows is usually low at 5 to 6 wk postpartum (BonDurant, 1999), and studies in which a benefit of i.u. administration of antibiotics on fertility was demonstrated did not evaluate subsequent uterine health or bacterial infection. Despite the low uterine bacterial contamination, subclinical endometritis was prevalent in lactating dairy 
cattle (Kasimanickam et al., 2004; Gilbert et al., 2005; Rutigliano et al., 2008), suggesting that endometrial inflammation is not always concurrent with bacterial infection. Nonetheless, a recent study observed that presence of Arcanobacterium pyogenes or Prevotella melaninogenica explained $48 \%$ of the variance in polymorphonuclear neutrophil counts at 49 DIM (Gilbert et al., 2007). Therefore, antibiotics may improve fertility in cows diagnosed with clinical or subclinical endometritis by reducing bacterial contamination of the uterus and concurrent inflammation.

Currently in the United States there is no approved antibiotic for i.u. administration in dairy cows; however, ceftiofur hydrochloride (Excenel RTU EZ, Pfizer Animal Health, New York, NY), a broad-spectrum third-generation cephalosporin in an oil suspension, is approved for systemic administration for treatment of metritis in postpartum dairy cows. A formulation containing ceftiofur hydrochloride equivalent to 125 $\mathrm{mg}$ of ceftiofur in $10 \mathrm{~mL}$ of oil-based sterile suspension packaged in a disposable syringe (Spectramast LC, Pfizer Animal Health) is labeled for therapy of clinical mastitis. This preparation is convenient for i.u. infusion with the aid of an infusion pipette and is expected to result in no withholding period for milk based on milk residue guidelines established for systemic ceftiofur hydrochloride at doses up to $2.2 \mathrm{mg} / \mathrm{kg}$ of BW. Although i.u. infusion of $500 \mathrm{mg}$ of cephapirin benzathine suspension in $5 \mathrm{~mL}$ of oil base improved reproductive performance of cows with clinical and subclinical endometritis, it is not known if i.u. antibiotic would benefit fertility of cows already receiving $\mathrm{PGF}_{2 \alpha}$ for routine estrous synchronization. It is known that i.u. treatment with antibiotics or injection of $\mathrm{PGF}_{2 \alpha}$ improved fertility of dairy cows previously diagnosed with subclinical endometritis (Kasimanickam et al., 2005), but whether the effects are additive is unknown.

It was hypothesized that clinical uterine diseases would be detrimental to fertility of dairy cows because of increased risk of subclinical endometritis, but a single i.u. treatment with ceftiofur hydrochloride would reduce bacterial contamination of the uterus and prevalence of subclinical endometritis. Ultimately, i.u. treatment with ceftiofur was expected to improve reproductive performance of dairy cows. Improvements in fertility from i.u. treatment were expected only in cows previously diagnosed with metritis or clinical endometritis despite the use of $\mathrm{PGF}_{2 \alpha}$. Therefore, the objectives were to determine the effects of a single i.u. infusion of $125 \mathrm{mg}$ of ceftiofur hydrochloride on uterine health, pregnancy per AI, pregnancy loss, and interval from calving to pregnancy in lactating dairy cows already receiving $\mathrm{PGF}_{2 \alpha}$ for estrous synchronization and previously diagnosed or not with clinical uterine disease.

\section{MATERIALS AND METHODS}

\section{Animals, Housing, and Feeding}

Eight hundred and twelve Holstein cows (591 primiparous and 221 multiparous) from a commercial dairy farm with 5,400 lactating dairy cows in the San Joaquin Valley (California) were used. Cows were enrolled from October to December 2005, and the 3.5\% FCM rollingherd average during the study year was $11,100 \mathrm{~kg} / \mathrm{cow}$ with average $( \pm$ SEM $)$ daily milk yield for the enrolled primiparous and multiparous cows of $32.4 \pm 0.25$ and $38.9 \pm 0.41 \mathrm{~kg} / \mathrm{d}$, respectively. Cows were fed the same diet as a TMR once daily, which was formulated using the CPM Dairy software (version 3.0.8; Miner Institute, Chazy, NY) to meet or exceed the dietary requirements for a lactating cow weighing $680 \mathrm{~kg}$ and producing $40 \mathrm{~kg}$ of $3.5 \% \mathrm{FCM}$ when consuming $23 \mathrm{~kg} / \mathrm{d}$ of DM (NRC, 2001).

Cows were housed in freestall barns and primiparous and multiparous cows were grouped separately. Cows were milked thrice daily and yield of milk was measured and recorded daily for individual cows. Average yield during the first $8 \mathrm{wk}$ was used to determine the effect of milk yield on reproductive responses. All cows had their body condition scored using a 5 -point $(1=$ thin to $5=$ fat) system (Ferguson et al., 1994) at $44 \pm$ 3 DIM.

\section{Evaluation of Clinical Uterine Diseases}

Cows were evaluated daily for signs of metritis by the herd personnel in the first 14 DIM. Metritis was characterized by the presence of watery, fetid vaginal discharge and rectal temperature $>39.5^{\circ} \mathrm{C}$. Cows with metritis received ceftiofur hydrochloride for 5 consecutive days at a dose of $2.2 \mathrm{mg} / \mathrm{kg}$ of BW (ceftiofur hydrochloride sterile suspension, Excenel RTU EZ, Pfizer Animal Health). Clinical endometritis was evaluated at $44 \pm 3$ DIM, in the last 7 weekly cohorts of cows $(547$ cows; 432 primiparous and 115 multiparous) enrolled in the study, by retrieving vaginal mucus using the Metricheck device (Metricheck, SimcroTech, Hamilton, New Zealand) as described previously (McDougall et al., 2007). Cows having mucopurulent or purulent discharge were classified as having clinical endometritis as previously reported (Sheldon et al., 2006; McDougall et al., 2007).

\section{Uterine Culture and Cytology}

Two hundred and two cows (148 primiparous and 54 multiparous) within the subset of 547 cows evaluated for clinical endometritis had a low-volume aseptic 
uterine lavage at $51 \pm 3$ DIM (7 d after treatment) and immediately before receiving the second $\mathrm{PGF}_{2 \alpha}$ of the estrous synchronization protocol, for bacteriology and cytology. Briefly, after thorough sanitation of the vulva and entrance of the vagina, an 18 French, 30$\mathrm{mL}, 56-\mathrm{cm}$, autoclaved 2-way Foley catheter was placed randomly in 1 of the uterine horns at approximately 5 $\mathrm{cm}$ past the bifurcation of the uterus. The catheter was protected by a sanitary sheath that was broken immediately before the catheter passed through the opening of the cervix. The cuff of the catheter was inflated with 7 to $10 \mathrm{~mL}$ of air according to the diameter of the uterine horn, and $20 \mathrm{~mL}$ of sterile isotonic saline solution was infused into the uterine horn and then recovered using a $35-\mathrm{mL}$ sterile syringe. Ten milliliters of the aspirated fluid was transferred to a sterile plastic tube, placed in ice, and transported to the laboratory within $4 \mathrm{~h}$ of collection. In the laboratory, the aspirated fluid was agitated and a sterile cotton swab was used to streak the uterine fluid onto blood agar and MacConkey plates. Plates were incubated for $48 \mathrm{~h}$ in aerobic conditions and then submitted to the Animal Health and Food Safety Laboratory System (Tulare, CA) for bacterial speciation. Plates containing a single colony-forming unit were considered a positive bacterial growth and plates with 3 types of colonies were considered mixed bacterial growth.

The same tubes with uterine flush were used for cytological evaluation of the uterus. Briefly, the tubes were centrifuged at $750 \times g$ for $10 \mathrm{~min}$ and the supernatant discarded. The pellet was resuspended with $2 \mathrm{~mL}$ of saline, and an aliquot of $20 \mu \mathrm{L}$ was pipetted onto glass slides and smeared in 2 slides per flush. Smears were air-dried and stained using the Diff-Quick (Fisher Diagnostics, Middletown, VA) stain. Slides were examined under a microscope and the number of total leukocytes, epithelial endometrial cells, and neutrophils were counted to complete 100 cells per slide, and percentage neutrophils was calculated. Subclinical endometritis was defined when the proportion of neutrophils $\geq 5 \%$ (Gilbert et al., 2005).

\section{Treatments, Al, and Pregnancy Diagnosis}

Weekly, a cohort of 80 to 120 cows at $44 \pm 3$ DIM was stratified by parity, previous diagnosis of metritis, and other illnesses (pneumonia, ketosis, indigestion, mastitis, and lameness) in the first 44 DIM and, within each block, randomly assigned to 1 of 2 treatments (Figure 1). Treatments were an i.u. infusion of a 10-mL suspension (Spectramast LC, Pfizer Animal Health) containing $125 \mathrm{mg}$ of ceftiofur as ceftiofur hydrochloride (ceftiofur; $\mathrm{n}=396$ ) or no i.u. treatment (control; $\mathrm{n}$ $=416)$. The dose selected was based on milk ceftiofur concentrations when cows milked twice daily received 2 intramammary infusions of $125 \mathrm{mg}$ of ceftiofur hydrochloride $24 \mathrm{~h}$ apart. In these cows, the mean concentration of ceftiofur and its residues in milk remained above $0.50 \mu \mathrm{g} / \mathrm{mL}$ for up to 4 milkings after the second treatment (Spectramast LC data sheet, Pfizer Animal Health). It was expected that a single i.u. infusion of $125 \mathrm{mg}$ of ceftiofur would result in concentrations of ceftiofur in uterine fluids greater than those observed in the milk of cows considering the volume of the uterine lumen at $44 \pm 3$ DIM relative to a mammary gland, and that there was no intentional removal of uterine content after treatment when compared with milking following intramammary infusion. Ceftiofur $>0.50 \mu \mathrm{g} /$ $\mathrm{mL}$ is above the minimum inhibitory concentration for 90\% of Escherichia coli and Arcanobacterium pyogenes in vitro (Sheldon et al., 2004).

In the subset of 547 cows evaluated for clinical endometritis, 271 received ceftiofur and 276 remained as controls. For the subset of 202 cows evaluated for subclinical endometritis and uterine culture, 97 received ceftiofur and 105 remained as controls. Cows receiving ceftiofur i.u. were subjected to no milk withholding but a 48-h meat withdrawal to follow the current label recommendations for systemic administration of up to 2.2 $\mathrm{mg}$ of ceftiofur hydrochloride per $\mathrm{kg}$ of BW.

For the first AI, all cows received the same synchronization of estrus and timed AI protocol, which consisted of 2 s.c. injections of $25 \mathrm{mg}$ of $\mathrm{PGF}_{2 \alpha}(5 \mathrm{~mL}$ of Lutalyse sterile solution, dinoprost tromethamine, Pfizer Animal Health) at $37 \pm 3$ and $51 \pm 3$ DIM. For the subset of 202 cows subjected to uterine culture and cytology, the injection of $\mathrm{PGF}_{2 \alpha}$ on $\mathrm{d} 51 \pm 3$ was administered only after lavage of the uteri. Cows observed in estrus after the second $\mathrm{PGF}_{2 \alpha}$ were inseminated, and those not detected in estrus were enrolled in a timed AI protocol 14 d later. The timed AI consisted of a 100- $\mu$ g injection of GnRH i.m. (2 $\mathrm{mL}$ of Cystorelin, gonadorelin diacetate tetrahydrate, Merial Ltd., Iselin, NJ) at $65 \pm 3$ DIM, followed $7 \mathrm{~d}$ later $(72 \pm 3 \mathrm{DIM})$ by an s.c. injection of $25 \mathrm{mg}$ of $\mathrm{PGF}_{2 \alpha}$, and an i.m. injection of $1.0 \mathrm{mg}$ of estradiol cypionate $(0.5 \mathrm{~mL}$ of estradiol cypionate, Pfizer Animal Health) at $73 \pm 3$ DIM, and timed AI performed $48 \mathrm{~h}$ after the estradiol cypionate injection (Cerri et al., 2004). For the second and later AI, cows were inseminated upon detection of spontaneous estrus or following the same timed AI protocol used for first AI after nonpregnancy diagnosis. Estrus was detected once daily, in the morning, and cows in estrus were those with removed tail paint (All-weather Paintstik, LA-CO Industries, Chicago, IL) that was applied daily to the tail head (Macmillan et al., 1988).

Cows were examined for pregnancy by palpation per rectum at $38 \pm 3$ and $180 \pm 7 \mathrm{~d}$ after AI. Cows not con- 


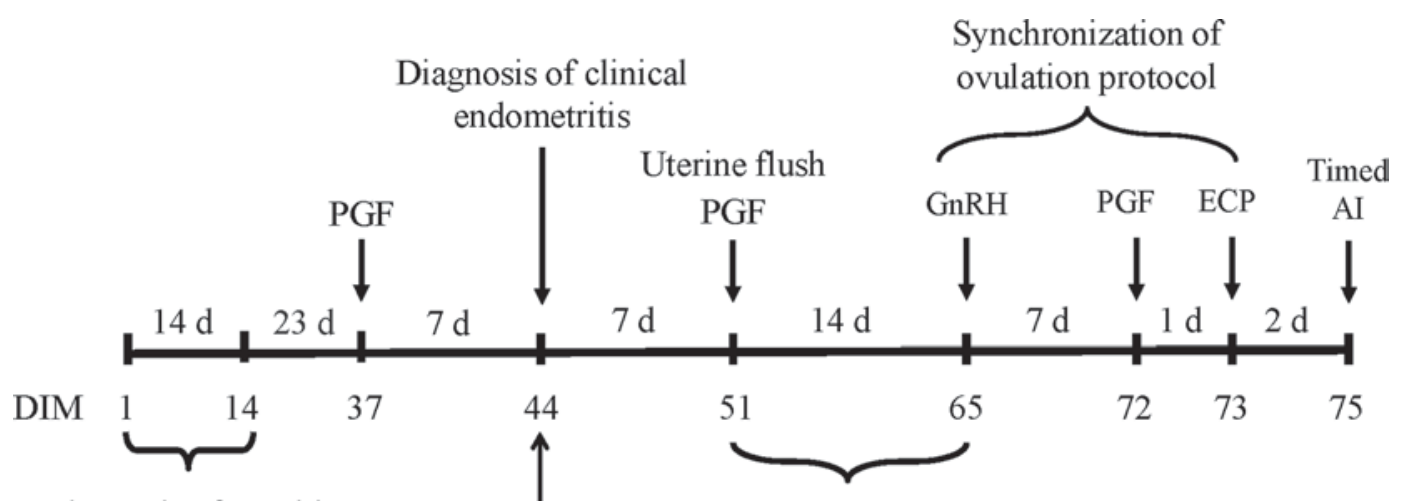

Diagnosis of metritis

Estrous detection and AI

\pm uterine infusion of

$125 \mathrm{mg}$ of ceftiofur

Figure 1. Diagram of activities during the study. ECP = injection of $1.0 \mathrm{mg}$ of estradiol cypionate; $\mathrm{GnRH}=$ injection $100 \mu \mathrm{g}$ of $\mathrm{GnRH}$; metritis = diagnosis of metritis; clinical endometritis = diagnosis of clinical endometritis; $\mathrm{PGF}=$ injection of $25 \mathrm{mg}$ of $\mathrm{PGF}_{2 \alpha}$; uterine flush $=$ flush of the uterus for microbiological culture and diagnosis of subclinical endometritis.

ceiving to the first AI were re-examined for pregnancy after each subsequent insemination at $38 \pm 3 \mathrm{~d}$ after AI until 300 DIM. The detection of an embryonic vesicle was used as indicator of pregnancy at $38 \pm 3 \mathrm{~d}$ after $\mathrm{AI}$ and the presence of an enlarged uterus filled with fluid, balloting of the fetus, and presence of fremitus of the median uterine artery indicated pregnancy at 180 $\pm 7 \mathrm{~d}$ of gestation. First-service pregnancy per AI was defined as the number of pregnant cows divided by the number of cows receiving AI in each treatment at $38 \pm$ 3 and $180 \pm 7 \mathrm{~d}$ after insemination. Cows diagnosed as pregnant on d $38 \pm 3$ and diagnosed as nonpregnant on d $180 \pm 7$ after AI had pregnancy loss.

\section{Statistical Analyses}

The experimental design was a randomized block design. Weekly, cows were blocked as described previously and randomly assigned to 1 of the 2 treatments. The sample sizes of 812 cows in the study and the 547 cows evaluated for clinical endometritis were calculated (Minitab Inc., State College, PA) to detect treatment differences in pregnancy per AI of at least 8 percentage units $(\alpha=0.05$ and $\beta=0.20)$. It was estimated that prevalence of subclinical endometritis would be approximately 30 to $40 \%$ at 51 DIM (Gilbert et al., 2005 ), and that treatment would reduce prevalence by 15 percentage units (e.g., 35 vs. 20\%). For that, 100 cows per treatment were required to detect a statistical difference $(\alpha=0.05$ and $\beta=0.20)$.

Univariate analyses were performed by chi-square analysis using the FREQ procedure (SAS Inst. Inc., Cary, NC) to evaluate the association between treat- ment, metritis, clinical endometritis, subclinical endometritis, and positive bacterial cultures for the subset of 202 cows. Proportion of cows with positive culture was analyzed both including and excluding the 7 cows with mixed bacterial growth ( $>2$ types of bacterial colonies in the culture plate). Because results were similar, cows with mixed bacterial cultures were included in the analysis.

The effects of treatment on prevalence of positive bacterial culture, subclinical endometritis, pregnancy per AI, and pregnancy loss were all analyzed by logistic regression with the LOGISTIC procedure of SAS. The logistic regression models for pregnancy per AI and pregnancy loss included the effects of treatment, parity (primiparous vs. multiparous), metritis, stillbirth or twin calvings, other illnesses (pneumonia, ketosis, indigestion, mastitis, and lameness), BCS ( $<2.75$ vs. $\geq 2.75$ ), method of AI (AI upon detection of estrus or timed AI), low-volume uterine lavage at 51 DIM (yes or no), milk yield in the first 8 wk postpartum (above vs. below the mean yield for primiparous and multiparous), and interactions between treatment and covariates. For the subset of 547 cows evaluated for clinical endometritis, the models for analyses of pregnancy per AI and pregnancy loss included the effect of clinical endometritis and its interaction with treatment. In all models, a backward stepwise regression was used and the elimination was performed by the Wald statistic criterion when $P>0.15$, and treatment was forced in the final models.

The hazard of pregnancy (adjusted hazard ratio, AHR) in the first 300 DIM was analyzed by Cox's proportional hazard model using the PHREG procedure of 
GALVÃO ET AL.

Table 1. Bacterial isolates from uterine flushes performed in 202 cows at $51 \pm 3 \mathrm{DIM}^{1}$

\begin{tabular}{lcc}
\hline Bacterial isolate & Cows, $\%(\mathrm{n} / \mathrm{n}$ total $)$ & Isolates, \% (n/n total) \\
\hline Arcanobacterium pyogenes & $4.5(9 / 202)$ & $13.2(9 / 68)$ \\
Bacillus spp. & $7.9(16 / 202)$ & $23.5(16 / 68)$ \\
Enterococcus spp. & $0.5(1 / 202)$ & $1.5(1 / 68)$ \\
Escherichia coli & $2.5(5 / 202)$ & $7.4(5 / 68)$ \\
Lactobacillus spp. & $0.5(1 / 202)$ & $1.5(1 / 68)$ \\
Mannheimia hemolytica & $1.0(2 / 202)$ & $2.9(2 / 68)$ \\
Pasteurella multocida & $2.0(4 / 202)$ & $5.9(4 / 68)$ \\
Salmonella dublin & $1.0(2 / 202)$ & $2.9(2 / 68)$ \\
Staphylococcus spp. & $8.4(17 / 202)$ & $25.0(17 / 68)$ \\
Streptococcus spp. & $2.0(4 / 202)$ & $5.9(4 / 68)$ \\
Mixed bacterial growth & $3.5(7 / 202)$ & $10.3(7 / 68)$ \\
\hline
\end{tabular}

${ }^{1}$ All cows received an injection of $25 \mathrm{mg} \mathrm{PGF}$ P $_{2 \alpha}$ at $37 \pm 3$ DIM and 97 of the 202 cows received intrauterine infusion of $125 \mathrm{mg}$ ceftiofur hydrochloride at $44 \pm 3$ DIM. There were 58 cows with positive uterine culture and 68 isolates because 10 cows had 2 isolates. Seven cows with 3 different bacterial isolates were considered as mixed growth.

SAS. This analysis estimated the hazard of a cow being pregnant at a given time; therefore, it measured the rate of pregnancy (rate at which cows become pregnant). The time variable used in the model was the interval in days between calving and pregnancy detected $38 \mathrm{~d}$ after AI. Cows that were sold, died, or remained nonpregnant at 300 DIM were censored. The Cox's model included the effects of treatment, parity, stillbirth and/or twin calvings, metritis, other postpartum illnesses, BCS, method of AI for first postpartum AI, milk yield in the first $8 \mathrm{wk}$ postpartum, and the interaction between treatment and covariates. Proportionality of hazard rate was evaluated by inclusion of interactions between explanatory variables and time and by evaluation of the Kaplan-Meier curves. For the subset of cows evaluated for clinical endometritis, the latter was also included in the statistical model. For the subset of cows subjected to uterine flush, the effects of subclinical endometritis and positive bacterial culture were also included in the statistical model. Explanatory variables were retained only when their main effect or the interaction with treatment resulted in $P \leq 0.15$, and treatment was forced in the final models. The median and mean days to pregnancy were obtained by survival analysis from the Kaplan-Meier model using the LIFETEST procedure of SAS. The survival plot was generated using the survival option of MedCalc version 9.2 for Windows (MedCalc Software, Mariakerke, Belgium).

Differences with $P \leq 0.05$ were considered significant and $0.05<P \leq 0.10$ were considered a tendency.

\section{RESULTS}

There were 58 cows with positive cultures, resulting in a total of 68 bacterial isolates (Table 1). The main isolates were CNS, Bacillus spp., and A. pyogenes, which were found in $8.4,7.9$, and $4.5 \%$ of the cows and represented $25.0,23.5$, and $13.2 \%$ of the isolates, respectively. Escherichia coli was found in $2.5 \%$ of the cows and represented $7.4 \%$ of the isolates. Metritis within the first 14 DIM did not influence the prevalence of positive cultures at $51 \pm 3$ DIM. Clinical endometritis at $44 \pm 3$ DIM was the uterine disease most associated with positive bacterial culture at $51 \pm 3$ DIM; cows with clinical endometritis were more likely $(P<$ $0.05)$ to have A. pyogenes, E. coli, and overall positive cultures (Table 2). Cows with subclinical endometritis had increased $(P=0.02)$ prevalence of $A$. pyogenes, but subclinical endometritis was not associated with $E$. coli and positive bacterial cultures.

Univariate analysis demonstrated that treatment with ceftiofur at $44 \pm 3$ DIM did not decrease the overall prevalence of positive bacterial culture; however, it decreased $(P=0.04)$ the prevalence of $A$. pyogenes at $51 \pm 3$ DIM (Table 2). Multivariate analysis for cows diagnosed with metritis demonstrated no effect of ceftiofur on the prevalence of positive bacterial culture (Table 3). On the other hand, a tendency for an interaction $(P=0.08)$ between ceftiofur and clinical endometritis was observed for the prevalence of positive bacterial culture (Table 4). Parity and BCS affected the prevalence of positive bacterial cultures at $51 \pm$ 3 DIM; multiparous cows (44.4 vs. $23.0 \% ; P=0.004$ ) and cows with $\mathrm{BCS} \leq 2.75$ (44.4 vs. $23.0 \% ; P=0.02$ ) had increased prevalence of positive bacterial cultures compared with primiparous cows and cows with BCS $>2.75$, respectively.

Cows diagnosed with metritis in the first 14 DIM were more likely $(P=0.02)$ to have clinical endometritis at $44 \pm 3$ DIM (44.6 vs. $28.5 \%$ ), and cows with clinical endometritis tended $(P=0.08)$ to have increased prevalence of subclinical endometritis at 51 \pm 3 DIM compared with cows without clinical endometritis (36.8 vs. $25.4 \%$; Table 4). Nevertheless, there 
Table 2. Effect of treatment, metritis, clinical endometritis, and subclinical endometritis on prevalence of overall positive uterine culture, positive culture of Arcanobacterium pyogenes, Escherichia coli, and other bacteria at $51 \pm 3$ DIM

\begin{tabular}{lllll}
\hline Parameter & \multicolumn{1}{c}{ Overall } & A. pyogenes & E. coli & Other bacteria \\
\hline Treatment $^{1}$ & & & & \\
$\quad$ Ceftiofur, \% (n/n) & $24.7(24 / 97)$ & $1.0(1 / 97)^{\mathrm{a}}$ & $2.1(2 / 97)$ & $21.6(21 / 97)$ \\
$\quad$ Control, \% (n/n) & $32.4(34 / 105)$ & $7.6(8 / 105)^{\mathrm{b}}$ & $2.9(3 / 105)$ & $21.9(23 / 105)$ \\
Metritis $^{2}$ & & & \\
$\quad$ Yes, \% (n/n) & $29.2(19 / 65)$ & $4.6(3 / 65)$ & $3.1(2 / 65)$ & $21.5(14 / 65)$ \\
No, \% (n/n) & $28.5(39 / 137)$ & $4.4(6 / 137)$ & $2.2(3 / 137)$ & $21.9(30 / 137)$ \\
Clinical endometritis & & & & \\
$\quad$ Yes, \% (n/n) & $41.2(28 / 68)^{\mathrm{a}}$ & $10.3(7 / 68)^{\mathrm{a}}$ & $5.9(4 / 68)^{\mathrm{a}}$ & $25.0(17 / 68)$ \\
No, \% (n/n) & $22.4(30 / 134)^{\mathrm{b}}$ & $1.5(2 / 134)^{\mathrm{b}}$ & $0.8(1 / 134)^{\mathrm{b}}$ & $20.1(27 / 134)$ \\
Subclinical endometritis & & & & \\
$\quad$ Yes, \% (n/n) & $30.5(18 / 59)$ & $10.2(6 / 59)^{\mathrm{a}}$ & $0.0(0 / 59)$ & $20.3(12 / 59)$ \\
No, \% (n/n) & $28.0(40 / 143)$ & $2.1(3 / 143)^{\mathrm{b}}$ & $3.5(5 / 143)$ & $22.4(32 / 143)$ \\
\hline
\end{tabular}

${ }^{\mathrm{a}, \mathrm{b}}$ Within the same parameter, superscripts in the same column differ $(P \leq 0.05)$.

${ }^{1}$ Ceftiofur $=$ intrauterine infusion of $125 \mathrm{mg}$ of ceftiofur hydrochloride at $44 \pm 3$ DIM; control = no intrauterine infusion. All cows received an injection of $25 \mathrm{mg}$ of $\mathrm{PGF}_{2 \alpha}$ at $37 \pm 3$ DIM.

${ }^{2}$ Metritis $=$ presence of fetid vaginal discharge concurrent with rectal temperature $>39.5^{\circ} \mathrm{C}$ in the first 14 DIM

${ }^{3}$ Clinical endometritis $=$ presence of mucopurulent or purulent vaginal mucus at $44 \pm 3 \mathrm{DIM}$.

${ }^{4}$ Subclinical endometritis $=$ presence of $\geq 5 \%$ neutrophils in the uterine cytology at $51 \pm 3$ DIM.

was no association between metritis in the first 14 DIM and subclinical endometritis at $51 \pm 3$ DIM $(27.7 \%$ for cows diagnosed with metritis vs. $29.9 \%$ for cows not diagnosed with metritis; Table 3). Cows treated with i.u. ceftiofur at $44 \pm 3$ DIM had similar prevalence of subclinical endometritis at $51 \pm 3$ DIM compared with controls (30.9 vs. $27.6 \%$; Table 3 ). Although treatment with ceftiofur reduced the prevalence of positive uterine culture in cows with clinical endometritis, it did not affect the prevalence of subclinical endometritis in cows previously diagnosed with uterine disease (Tables 3 and 4).

When all cows were evaluated, i.u. infusion with ceftiofur did not affect pregnancy per AI at 38 [42.4 vs. $45.2 \%$; adjusted odds ratio $(\mathbf{A O R})=0.91 ; P=$
$0.51)$ and $180 \mathrm{~d}$ (36.9 vs. $38.4 \%$; $\mathrm{AOR}=0.95 ; P=$ $0.75)$ after the first postpartum insemination or pregnancy loss between 38 and $180 \mathrm{~d}$ (11.3 vs. 13.3\%) of gestation (Table 3 ). Cows with metritis had reduced $(P<0.03)$ pregnancy per AI at 38 (40.4 vs. 45.3\%; $\mathrm{AOR}=0.66)$ and $180 \mathrm{~d}(34.7$ vs. $39.0 \%$; $\mathrm{AOR}=0.70)$ after insemination; however, pregnancy loss was not different between cows with metritis and control cows $(12.5$ vs. $12.2 \%)$. An interaction $(P=0.004)$ between treatment and metritis was detected for pregnancy loss between 38 and $180 \mathrm{~d}$ after AI. Cows initially diagnosed with metritis receiving i.u. ceftiofur had greater $(P=$ $0.01)$ pregnancy loss than control cows (20.8 vs. $4.2 \%)$, whereas for cows without metritis, those treated with ceftiofur had less $(P=0.02)$ pregnancy loss than con-

Table 3. Effect of intrauterine infusion of ceftiofur hydrochloride at $44 \pm 3$ DIM on uterine health and fertility responses of cows previously diagnosed or not with metritis

\begin{tabular}{|c|c|c|c|c|c|c|c|}
\hline Variable & \multicolumn{4}{|c|}{ Metritis $^{1}$} & & & \\
\hline Positive culture & $22.6(7 / 31)$ & $35.3(12 / 34)$ & $25.8(17 / 66)$ & $31.0(22 / 71)$ & 0.22 & 0.35 & 0.38 \\
\hline Sub. endometritis ${ }^{3}$ & $35.5(11 / 31)$ & $20.6(7 / 34)$ & $28.8(19 / 66)$ & $31.0(22 / 71)$ & 0.44 & 0.48 & 0.18 \\
\hline \multicolumn{8}{|l|}{ Pregnancy per $\mathrm{AI}^{4}$} \\
\hline $\begin{array}{l}\text { Pregnancy loss } \\
\text { d } 38 \text { to } 180\end{array}$ & $20.8(10 / 46)$ & $4.2(2 / 48)$ & $7.0(8 / 114)$ & $16.5(22 / 133)$ & 0.35 & 0.72 & 0.004 \\
\hline
\end{tabular}

${ }^{1}$ Metritis = presence of fetid vaginal discharge concurrent with rectal temperature $>39.5^{\circ} \mathrm{C}$ in the first 14 DIM.

${ }^{2}$ Trt $=$ effect of treatment (ceftiofur vs. control); $\mathrm{M}=$ effect of metritis; Trt $\times \mathrm{M}=$ interaction between TRT and $\mathrm{M}$.

${ }^{3}$ Subclinical endometritis.

${ }^{4}$ There were 8 ceftiofur and 7 control cows diagnosed pregnant on d 38 after AI, but culled before pregnancy diagnosis on d 180 of gestation. 
Table 4. Effect of intrauterine infusion of ceftiofur hydrochloride at $44 \pm 3$ DIM on uterine health and fertility responses of cows previously diagnosed or not with clinical endometritis

\begin{tabular}{|c|c|c|c|c|c|c|c|}
\hline Variable & \multicolumn{4}{|c|}{ Clinical endometritis ${ }^{1}$} & & & \\
\hline Positive culture & $29.0(9 / 31)$ & $51.4(19 / 37)$ & $22.7(15 / 66)$ & $22.1(15 / 68)$ & 0.22 & 0.005 & 0.08 \\
\hline Sub. endometritis ${ }^{3}$ & $32.3(10 / 31)$ & $40.5(15 / 37)$ & $30.3(20 / 66)$ & $20.6(14 / 68)$ & 0.44 & 0.08 & 0.16 \\
\hline \multicolumn{8}{|l|}{ Pregnancy per $\mathrm{AI}^{4}$} \\
\hline \multicolumn{8}{|l|}{ Pregnancy loss } \\
\hline d 38 to 180 & $21.2(7 / 33)$ & $15.2(5 / 33)$ & $9.6(7 / 73)$ & $14.0(12 / 86)$ & 0.27 & 0.10 & 0.61 \\
\hline
\end{tabular}

${ }^{1}$ Clinical endometritis $=$ presence of mucopurulent or purulent vaginal mucus at $44 \pm 3$ DIM.

${ }^{2}$ Trt $=$ effect of treatment (ceftiofur vs. control); CE $=$ clinical endometritis; Trt $\times \mathrm{CE}=$ interaction between TRT and CE.

${ }^{3}$ Subclinical endometritis.

${ }^{4}$ One ceftiofur and 3 control cows were diagnosed pregnant on d 38 after AI, but culled before pregnancy diagnosis on d 180 of gestation.

trols (7.0 vs. $16.5 \%)$. Thirty-seven percent $(300 / 812)$ of all cows received timed AI, and their pregnancy to first service did not differ $(P=0.64)$ from that of cows inseminated upon detection of estrus [42.7\% (128/300) vs. $44.3 \%(227 / 512)]$. Furthermore, there was no interaction between method of AI and ceftiofur treatment on pregnancy to first AI. Parity and milk yield affected $(P<0.001)$ pregnancy per AI at 38 and $180 \mathrm{~d}$ after AI, and history of stillbirth and/or twins affected pregnancy per AI only at $180 \mathrm{~d}$ after AI. Primiparous cows had greater $(P<0.001)$ pregnancy per AI than multiparous cows at 38 (46.9 vs. $35.8 \%)$ and $180 \mathrm{~d}$ after AI (41.0 vs. $28.6 \%$ ), and cows with milk production below the mean milk yield had greater $(P<0.001)$ pregnancy per AI than cows with production above the mean at 38 (52.0 vs. $36.2 \%)$ and $180 \mathrm{~d}$ after AI (43.5 vs. $32.3 \%$ ). Finally, cows with a history of stillbirth or twins were less likely $(P=0.03)$ to be pregnant at $180 \mathrm{~d}$ after AI (26.5 vs. $38.8 \%$; AOR $=0.56)$ because of a 3.5 -fold increase $(P$ $=0.005)$ in the odds of pregnancy loss from 38 to 180 d after AI (29.0 vs. $10.6 \%$; AOR = 3.46).

The hazard of pregnancy in the first 300 DIM agreed with the findings of the logistic regression model; parity, metritis, and milk yield influenced pregnancy, whereas treatment had no effect. Treatment with ceftiofur did not affect the rate of pregnancy, resulting in median days to pregnancy of 81 and 80 for ceftiofur and control, respectively (Figure 2). The rate of pregnancy for multiparous cows was less than for primiparous cows $(\mathrm{AHR}=0.67)$, which resulted in extended $(P<0.001)$ median DIM at pregnancy (100 vs. 78 DIM). Cows initially diagnosed with metritis had reduced $(\mathrm{AHR}=$ $0.77 ; P=0.002$ ) pregnancy rate and extended interval to pregnancy ( 84 vs. 80 d). Finally, cows with milk production above the mean had reduced pregnancy rate $($ AHR $=0.93 ; P=0.001)$ compared with those below the mean resulting in median days open of 96 and 78 d, respectively. No interactions were observed between treatment and other explanatory variables for the rate of pregnancy in the Cox's model.

When the subset of 547 cows evaluated for clinical endometritis was considered in the statistical analysis, i.u. infusion with ceftiofur did not alter pregnancy per AI at 38 (39.9 vs. $44.2 \%$; $\mathrm{AOR}=0.87 ; P=0.41)$ and 180 d (34.2 vs. $37.4 \%$; AOR $=0.91 ; P=0.59)$ after AI (Table 4). Clinical endometritis did not influence (36.6 vs. $44.8 \% ; \mathrm{AOR}=0.74 ; P=0.11$ ) pregnancy per $\mathrm{AI}$ on d 38 after insemination; however, when pregnancy was evaluated on d 180 after insemination, cows diagnosed with clinical endometritis had reduced $(P=0.05)$ pregnancy per AI (29.7 vs. $38.9 \%$; AOR $=0.68$; Table 4 ). The hazard of pregnancy in the first 300 DIM for cows evaluated for clinical endometritis was not influenced by treatment (AHR $=0.91 ; P=0.28)$ and resulted in median days open of 90 and $80 \mathrm{~d}$ for ceftiofur and control, respectively. No interaction between treatment and clinical endometritis was observed for the hazard of pregnancy.

Cows with subclinical endometritis tended $(P=$ $0.06)$ to have lower pregnancy per AI on d 38 after the first postpartum insemination (27.9 vs. $40.7 \%$ ) and experienced a $26 \%$ reduction in pregnancy rate $(\mathrm{AHR}=0.74)$ in the first 300 DIM compared with cows without subclinical endometritis (Figure 3). The median interval to pregnancy was extended $17 \mathrm{~d}$ when cows were diagnosed with subclinical endometritis. On the other hand, having a positive bacterial culture at $51 \pm 3$ DIM did not affect $(P=0.78)$ the hazard of pregnancy $(\mathrm{AHR}=0.95)$.

\section{DISCUSSION}

Microbiological culture of the uterine lumen is known to result in a wide range of bacterial species, 


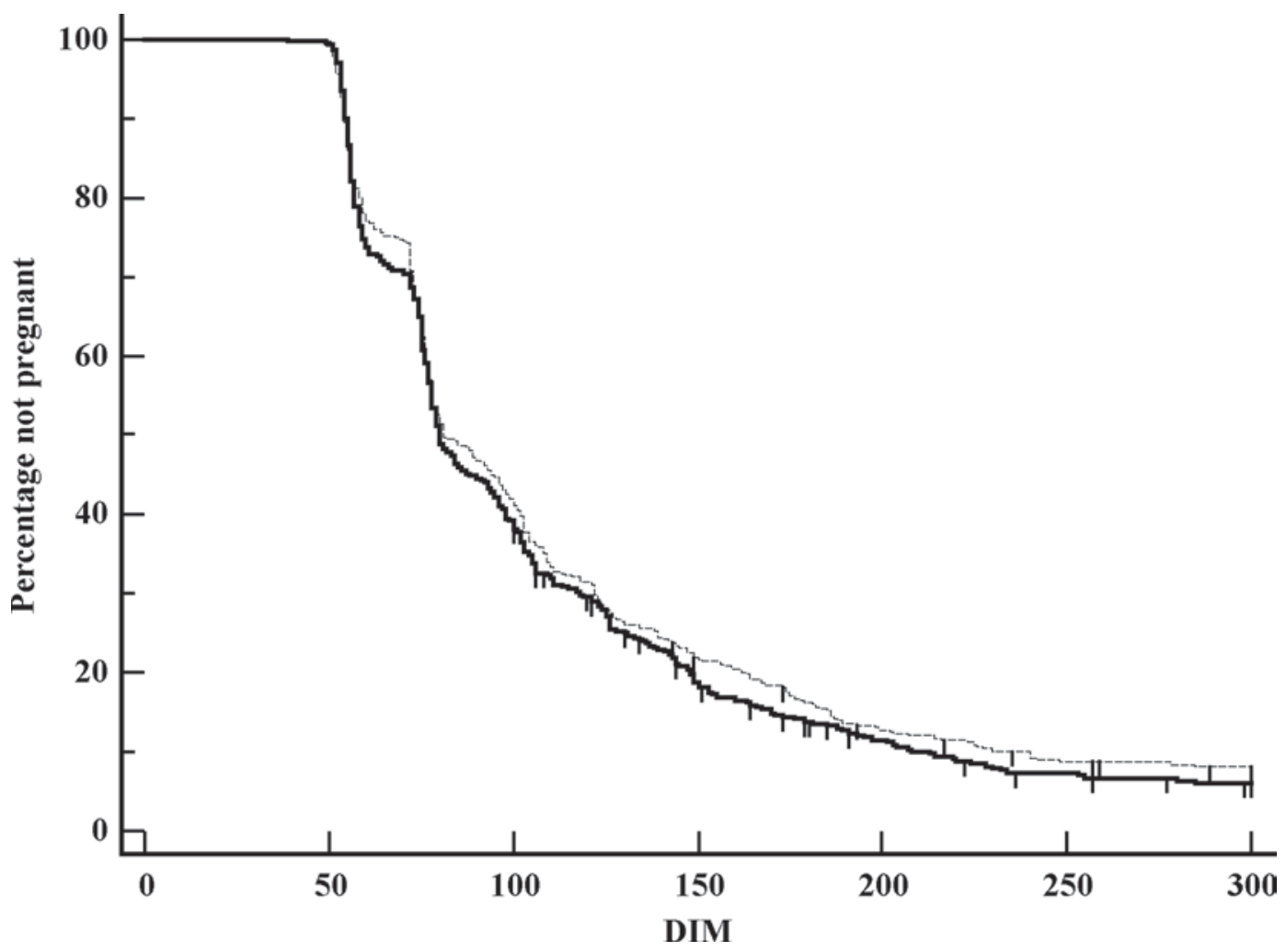

Figure 2. Survival curves for interval to pregnancy in dairy cows treated or not with ceftiofur at $44 \pm 3$ DIM. Pregnancy rate of cows treated with ceftiofur $(\mathrm{n}=396$; solid line) at $44 \pm 3$ DIM did not differ (adjusted hazard ratio $=0.93 ; 95 \%$ confidence interval $=0.80$ to $1.07 ; P=0.31$ ) from that of control cows $(\mathrm{n}=416$; dashed line). There was no interaction between treatment and history of metritis on the hazard of pregnancy. Median and mean (least squares means \pm SEM) days to pregnancy were, respectively, 81 and $113.9 \pm 3.5 \mathrm{~d}$ for cows treated with ceftiofur and 80 and $108.9 \pm 3.2 \mathrm{~d}$ for control cows. Tick marks in the curves represent censored cows.

and the aerobic bacteria isolated in this study were similar to those of previous reports (Griffin et al., 1974; BonDurant, 1999; Williams et al., 2005). Prevalence of positive bacterial growth was $24.7 \%$ in cows receiving i.u. ceftiofur and $32.4 \%$ in control cows. A wide range of prevalence of uterine bacterial infection exists from $9.0 \%$ between 46 and 60 DIM (Elliott et al., 1968) to as much as $25.0 \%$ at around 46 DIM (Griffin et al., 1974). Sheldon and Dobson (2004) summarized several studies and indicated that between 30 and 60 DIM, 7 to $50 \%$ of the cows had their uteri contaminated with bacteria. When aerobic and anaerobic bacteria were considered, Gilbert et al. (2007) observed that 36.0\% of the cows had a positive uterine culture at 49 DIM, although anaerobes were seldom isolated after the first week postpartum. Because of the difficulty culturing anaerobes and the anticipated low prevalence at 51 DIM (Bonnett et al., 1991; Gilbert et al., 2007), we opted to focus on aerobic bacteria such as $A$. pyogenes and E. coli, which are important pathogens involved in clinical and subclinical endometritis (Griffin et al., 1974; BonDurant, 1999; Williams et al., 2005; Gilbert et al., 2007).
Herein, this study confirmed the expected association between clinical endometritis and the prevalence of $A$. pyogenes and E. coli; however, subclinical endometritis was only associated with prevalence of $A$. pyogenes. Gilbert et al. (2007) observed that only A. pyogenes, and not E. coli, was associated with subclinical endometritis at 49 DIM. In the same study, presence of $E$. coli in the first week postpartum was associated with A. pyogenes at 49 DIM. Although E. coli was linked to clinical endometritis (Griffin et al., 1974; Williams et al., 2005), A. pyogenes was associated with severe and chronic cases of clinical endometritis (Griffin et al., 1974; Bonnett et al., 1991) and pyometra (BonDurant, 1999), which are known to suppress fertility of dairy cows. Clinical endometritis was associated with positive bacterial culture and subclinical endometritis. However, although metritis increased the risk of clinical endometritis, the former was not associated with positive bacterial culture or subclinical endometritis. In a previous study (Rutigliano et al., 2008), metritis doubled the odds of subclinical endometritis diagnosed before $\mathrm{PGF}_{2 \alpha}$ treatment; therefore, the absence of an association may be explained, in part, by a potential 


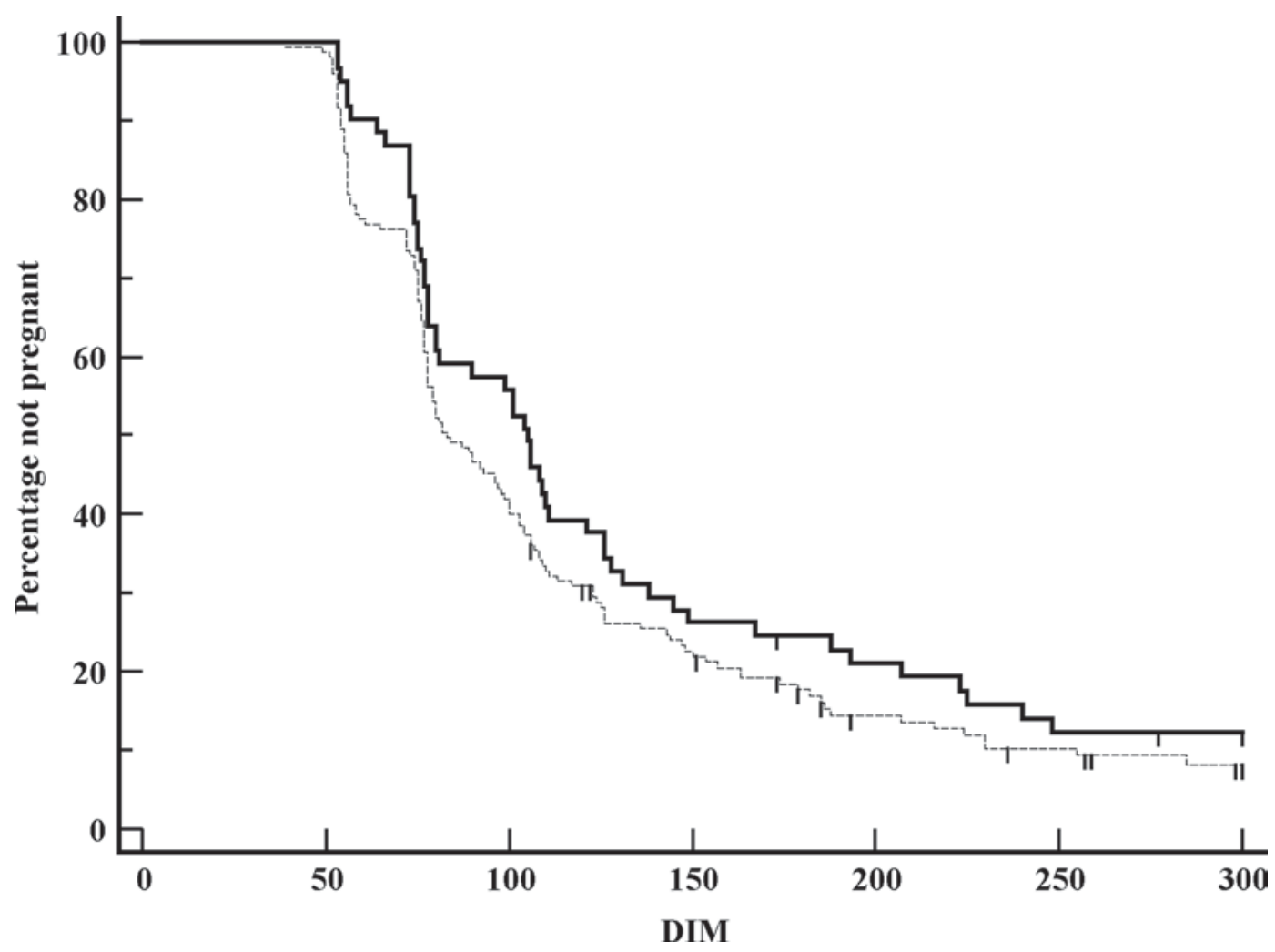

Figure 3. Survival curves for time to pregnancy in dairy cows with or without subclinical endometritis. Cows that had subclinical endometritis $(\mathrm{n}=59$; solid line) at $51 \pm 3$ DIM tended $(P=0.08)$ to have decreased (adjusted hazard ratio $=0.74 ; 95 \% \mathrm{CI}=0.53$ to 1.03$)$ pregnancy rate compared with cows not diagnosed with subclinical endometritis $(\mathrm{n}=143$; dashed line). Median and mean (least squares means $\pm \mathrm{SEM}$ ) days to pregnancy were, respectively, 105 and $126 \pm 8.8 \mathrm{~d}$ for cows with subclinical endometritis and 82 and $112.3 \pm 5.4 \mathrm{~d}$ for cows without subclinical endometritis. Tick marks in the curves represent censored cows.

effect of $\mathrm{PGF}_{2 \alpha}$ on uterine inflammation and infection in cows previously diagnosed with metritis.

Intrauterine infusion with ceftiofur was effective at reducing the prevalence of positive aerobic bacterial culture at $51 \pm 3$ DIM only in cows previously diagnosed with clinical endometritis, but not in those without clinical endometritis. Despite the benefits of i.u. ceftiofur at reducing infection in cows diagnosed with clinical endometritis, treatment did not influence the prevalence of subclinical endometritis at $51 \pm 3$ DIM. Arcanobacterium pyogenes was associated with increased prevalence of subclinical endometritis, but the low prevalence of $A$. pyogenes in control cows receiving $\mathrm{PGF}_{2 \alpha}$ might have negated any benefit of i.u. ceftiofur to reduce subclinical endometritis. Furthermore, when only control cows were evaluated, $69 \%$ of those with subclinical endometritis did not have aerobic bacteria isolated from the uterus. Therefore, in cows receiving $\mathrm{PGF}_{2 \alpha}$, the majority of cases of subclinical endometritis were not necessarily associated with concurrent bacterial infection at the time of diagnosis. This lack of infection associated with inflammation likely explains the inability of i.u. antibiotic to reduce subclinical endometritis.
All 3 uterine diseases evaluated had negative effects on fertility of lactating cows. Metritis markedly reduced reproductive performance of dairy cows (Fourichon et al., 2000). Also, clinical endometritis reduced pregnancy to first postpartum AI (McDougall et al., 2007) and extended the interval from calving to pregnancy (LeBlanc et al., 2002; McDougall et al., 2007); however, in the present study, clinical endometritis only affected pregnancy per AI at $180 \mathrm{~d}$ after the first insemination, and did not influence interval to pregnancy. It is possible that the use of $\mathrm{PGF}_{2 \alpha}$ as part of the estrous synchronization program and the use of an ovulation synchronization protocol for cows not observed in estrus may have precluded an effect of clinical endometritis on time to pregnancy, as $\mathrm{PGF}_{2 \alpha}$ is the treatment of choice for endometritis in cows with a corpus luteum (Sheldon and Dobson, 2004). In addition to clinical disease, subclinical endometritis reduced pregnancy to first postpartum AI and the rate of pregnancy in the first 300 DIM. These responses were shown in cows receiving (Rutigliano et al., 2008) or not $\mathrm{PGF}_{2 \alpha}$ (Kasimanickam et al., 2004; Gilbert et al., 2005) as part of a postpartum routine estrous synchronization program. Nevertheless, treatment with ceftiofur did not reduce 
the prevalence of subclinical endometritis, nor did ceftiofur minimize the effects of subclinical endometritis on fertility of dairy cows. The exact mechanism by which an increased influx of neutrophils in the uterine lumen, in the absence of pus or clinical uterine disease, reduces pregnancy is not clear. Recent work on 135 nonsuperovulated lactating dairy cows inseminated at 51 DIM demonstrated that fertilization rate tended to be reduced in cows previously diagnosed with subclinical endometritis at 31 DIM (Cerri et al., 2009). Whether reduction in oocyte fertilization explains most of the reduction in reproductive performance of cows diagnosed with subclinical endometritis is unknown, but inflammation and cytokine production by leukocytes in the uterus can disrupt endometrial function (BonDurant, 1999; Sheldon and Dobson, 2004) and impair embryo development (Soto et al., 2003). The culture of in vitro-produced embryos for $2 \mathrm{~d}$ in a medium containing uterine fluid from a cow induced to have endometrial inflammation reduced development to the blastocyst stage and decreased embryonic cell number because of a reduction in trophectoderm cells (Hill and Gilbert, 2008). Previously, Kasimanickam et al. (2005) demonstrated that treatment of cows diagnosed with subclinical endometritis with a single i.u. infusion of $500 \mathrm{mg}$ of cephapirin benzathine improved pregnancy per AI and rate of pregnancy in a similar manner to a single injection of $\mathrm{PGF}_{2 \alpha}$. Our results indicate that treatment with a single i.u. infusion of $125 \mathrm{mg}$ of ceftiofur had no additive effects on fertility of cows already receiving of $\mathrm{PGF}_{2 \alpha}$ as part of a routine estrous synchronization program.

It is noteworthy that pregnancy per AI and hazard of pregnancy were not improved by i.u. treatment with ceftiofur in cows previously diagnosed with metritis or clinical endometritis. The incidence of subclinical endometritis increased in cows previously diagnosed with clinical uterine disease and retained placenta (Rutigliano et al., 2008). Although ceftiofur reduced isolation of pathogens that cause uterine disease, it was not sufficient to minimize the effect of clinical or subclinical uterine diseases on fertility. A single i.u. infusion of cephapirin benzathine at $40.9 \pm 13.8$ (mean $\pm \mathrm{SD}$; range $=14$ to 107; McDougall, 2001) and at $30 \pm 3$ DIM (LeBlanc et al., 2002) improved reproductive performance of cows with a history of retained fetal membranes, stillbirths, or a vulval discharge after 13 DIM (McDougall, 2001) and of cows with clinical endometritis (LeBlanc et al., 2002). In the study by LeBlanc et al. (2002), cephapirin was beneficial in cows with a palpable corpus luteum. In the current study, presence of a corpus luteum was not evaluated, preventing assessment of a differential effect of i.u. infusion in cows according to their ovarian statuses or stage of the estrous cycle when they received the i.u. treatment. When used systemically, ceftiofur hydrochloride reached high concentrations in uterine tissues (Okker et al., 2002) sufficient to inhibit growth of pathogenic bacteria known to cause uterine disease in cows (Sheldon et al., 2004) and was effective in the treatment of metritis at $2.2 \mathrm{mg} / \mathrm{kg}$ for $5 \mathrm{~d}$ (Chenault et al., 2004). The inability of a single i.u. infusion of 125 $\mathrm{mg}$ of ceftiofur to improve uterine health and fertility of cows in the current study was likely consequent to the systematic use of $\mathrm{PGF}_{2 \alpha}$, which is known to reduce uterine bacterial contamination and improve fertility (Sheldon and Dobson, 2004; Kasimanickam et al., 2005). These cows treated with $\mathrm{PGF}_{2 \alpha}$ may not benefit from i.u. antibiotics. Although effective at reducing pathogenic bacteria in the uterus, it is possible that either the dosage or the duration of treatment with i.u. ceftiofur might have not been adequate to optimize fertility.

The lack of bacterial association with most cases of subclinical endometritis suggests that the deleterious effects of subclinical endometritis on fertility may be independent of concurrent bacterial infection when the diagnosis is performed and might require a different therapeutic approach to improve fertility of cows already receiving routine treatments with $\mathrm{PGF}_{2 \alpha}$.

\section{CONCLUSIONS}

Cows diagnosed with metritis in the first $2 \mathrm{wk}$ postpartum were more likely to develop clinical endometritis at $44 \pm 3$ DIM, which subsequently led to an increased risk of subclinical endometritis at $51 \pm 3$ DIM. Cows diagnosed with clinical endometritis at 44 \pm 3 DIM had increased overall prevalence of positive bacterial cultures and isolation of bacteria known to cause uterine disease (A. pyogenes and E. coli) at $51 \pm$ 3 DIM. Subclinical endometritis was associated with A. pyogenes and, although i.u. infusion with ceftiofur reduced the prevalence of $A$. pyogenes, it did not reduce subclinical endometritis. Pregnancy per AI and hazard of pregnancy were decreased by clinical and subclinical uterine diseases, but i.u. infusion of $125 \mathrm{mg}$ of ceftiofur did not improve pregnancy per AI following the first postpartum insemination or the rate of pregnancy in the first 300 DIM. The lack of benefits from i.u. infusion of $125 \mathrm{mg}$ of ceftiofur at $44 \pm 3$ DIM in cows already receiving $\mathrm{PGF}_{2 \alpha}$ was observed regardless of previous clinical uterine diseases. These data do not support the use of a single i.u. infusion with $125 \mathrm{mg}$ of ceftiofur hydrochloride at $44 \mathrm{~d}$ postpartum to improve uterine health or reproductive performance of lactating dairy cows routinely receiving $\mathrm{PGF}_{2 \alpha}$ as part of an estrous synchronization program. 


\section{ACKNOWLEDGMENTS}

The authors thank the owner and staff of the collaborating dairy for use of their cows and facilities. We thank Felton Medical for donation of the Metrichek device and Kathy Glenn from the milk quality laboratory at the Veterinary Medicine Teaching and Research Center (University of California Davis) for assisting with the microbiological analyses.

\section{REFERENCES}

Bartlett, P. C., J. H. Kirk, M. A. Wilke, J. B. Kaneene, and E. C. Mather. 1986. Metritis complex in Michigan Holstein-Friesian cattle: Incidence, descriptive epidemiology and estimated economic impact. Prev. Vet. Med. 4:235-248.

BonDurant, R. H. 1999. Inflammation in the bovine female reproductive tract. J. Anim. Sci. 77(Suppl. 2):101-110.

Bonnett, B. N., S. W. Martin, V. P. J. Gannon, R. B. Miller, and W. G. Etherington. 1991. Endometrial biopsy in Holstein-Friesian dairy cows: III. Bacterial analysis and correlations with histological findings. Can. J. Vet. Res. 55:168-173.

Cerri, R. L. A., H. M. Rutigliano, F. S. Lima, D. B. Araujo, and J. E. P. Santos. 2009. Effect of source of supplemental selenium on uterine health and embryo quality in high-producing dairy cows. Theriogenology doi:10.1016/j.theriogenology.2008.12.005

Cerri, R. L. A., J. E. P. Santos, S. O. Juchem, K. N. Galvão, and R. C. Chebel. 2004. Timed artificial insemination with estradiol cypionate or insemination at estrus in high-producing dairy cows. J. Dairy Sci. 87:3704-3715.

Chenault, J. R., J. F. McAllister, S. T. Jr. Chester, K. J. Dame, F. M. Kausche, and E. J. Robb. 2004. Efficacy of ceftiofur hydrochloride sterile suspension administered parenterally for the treatment of acute postpartum metritis in dairy cows. J. Am. Vet. Med. Assoc. 224:1634-1639.

Elliott, L., K. J. McMahon, H. T. Gier, and G. B. Marion. 1968. Uterus of the cow after parturition: Bacterial content. Am. J. Vet. Res. 29:77-81.

Ferguson, J. D., D. T. Galligan, and N. Thomsen. 1994. Principal descriptors of body condition score in Holstein cows. J. Dairy Sci. 77:2695-2703.

Fourichon, C., H. Seegers, and X. Malher. 2000. Effect of disease on reproduction in the dairy cow: A meta-analysis. Theriogenology 53:1729-1759.

Gilbert, R. O., N. R. Santos, K. N. Galvão, S. B. Brittin, and H. B. Roman. 2007. The relationship between postpartum uterine bacterial infection (BI) and subclinical endometritis (SE). J. Dairy Sci. 90(Suppl. 1):469. (Abstr)

Gilbert, R. O., S. T. Shin, C. L. Guard, H. N. Erb, and M. Frajblat. 2005. Prevalence of endometritis and its effects on reproductive performance of dairy cows. Theriogenology 64:1879-1888.

Griffin, J. F. T., P. J. Hartigan, and W. R. Nunn. 1974. Nonspecific uterine infection and bovine fertility I. Infection patterns and endometritis during the first seven weeks post-partum. Theriogenology 1:91-106.

Hill, J., and R. Gilbert. 2008. Reduced quality of bovine embryos cultured in media conditioned by exposure to an inflamed endometrium. Aust. Vet. J. 86:312-316.

Kasimanickam, R., T. F. Duffield, R. A. Foster, C. J. Gartley, K. E. Leslie, J. S. Walton, and W. H. Johnson. 2004. Endometrial cytology and ultrasonography for the detection of subclinical endometritis in postpartum dairy cows. Theriogenology 62:9-23.

Kasimanickam, R., T. F. Duffield, R. A. Foster, C. J. Gartley, K. E. Leslie, J. S. Walton, and W. H. Johnson. 2005. The effect of a single administration of cephapirin or cloprostenol on the reproductive performance of dairy cows with subclinical endometritis. Theriogenology 63:818-830.

LeBlanc, S. J., T. F. Duffield, K. E. Leslie, K. G. Bateman, G. P. Keefe, J. S. Walton, and W. H. Johnson. 2002. The effect of treatment of clinical endometritis on reproductive performance in dairy cows. J. Dairy Sci. 85:2237-2249.

Macmillan, K. L., V. K. Taufa, D. R. Barnes, A. M. Day, and R. Henry. 1988. Detecting estrus in synchronized heifers using tail paint and aerosol riddle. Theriogenology 30:1099-1114.

McDougall, S. 2001. Effect of intrauterine antibiotic treatment on reproductive performance of dairy cows following periparturient disease. N. Z. Vet. J. 49:150-158.

McDougall, S., R. Macaulay, and C. Compton. 2007. Association between endometritis diagnosis using a novel intravaginal device and reproductive performance in dairy cattle. Anim. Reprod. Sci. 99:9-23.

NRC. 2001. Nutrient Requirements of Dairy Cattle. 7th rev. ed., Natl. Acad. Sci. Washington, DC.

Okker, H., E. J. Schmitt, P. L. Vos, P. Scherpenisse, A. A. Bergwerff, and F. H. Jonker. 2002. Pharmacokinetics of ceftiofur in plasma and uterine secretions and tissues after subcutaneous postpartum administration in lactating dairy cows. J. Vet. Pharmacol. Ther. 25:33-38.

Rutigliano, H. M., F. S. Lima, R. L. A. Cerri, L. F. Greco, J. M. Vilela, V. Magalhães, F. T. Silvestre, W. W. Thatcher, and J. E. P. Santos. 2008. Effects of method of presynchronization and source of selenium on uterine health and reproduction in dairy cows. J. Dairy Sci. J. Dairy Sci. 91:3323-3336.

Sheldon, I. M., M. Bushnell, J. Montgomery, and A. N. Rycroft. 2004. Minimum inhibitory concentrations of some antimicrobial drugs against bacteria causing uterine infections in cattle. Vet. Rec. $155: 383-387$.

Sheldon, I. M., and H. Dobson. 2004. Postpartum uterine health in cattle. Anim. Reprod. Sci. 82-83:295-306.

Sheldon, I. M., G. S. Lewis, S. LeBlanc, and R. O. Gilbert. 2006 Defining postpartum uterine disease in cattle. Theriogenology 65:1516-1530.

Soto, P., R. P. Natzke, and P. J. Hansen. 2003. Actions of tumor necrosis factor-a on oocyte maturation and embryonic development in cattle. Am. J. Reprod. Immunol. 50:380-388.

Williams, E. J., D. P. Fisher, D. U. Pfeiffer, G. E. England, D. E. Noakes, H. Dobxon, and I. M. Sheldon. 2005. Clinical evaluation of postpartum vaginal mucus reflects uterine bacterial infection and the immune response in cattle. Theriogenology 63:102-117. 